\title{
Glutamic Acid Transporters: Targets for Neuroprotective Therapies in Parkinson's Disease
}

\section{OPEN ACCESS}

Edited by:

Santiago Perez-Lloret,

Consejo Nacional de Investigaciones Cientificas y Técnicas (CONICET),

Argentina

Reviewed by:

Christoph Fahlke,

Julich-Forschungszentrum,

Helmholtz-Verband Deutscher

Forschungszentren (HZ), Germany

Sinead M. O'Donovan,

University of Toledo, United States

*Correspondence:

Xiang $\mathrm{Li}$

lix2009@126.com

Fancai Zeng

zfcai@swmu.edu.cn

${ }^{\dagger}$ These authors have contributed equally to this work

Specialty section:

This article was submitted to

Neuropharmacology,

a section of the journal

Frontiers in Neuroscience

Received: 09 March 2021

Accepted: 07 May 2021

Published: 16 June 2021

Citation:

Li X, Wang W, Yan J and Zeng F (2021) Glutamic Acid Transporters: Targets for Neuroprotective Therapies in Parkinson's Disease.

Front. Neurosci. 15:678154. doi: 10.3389/fnins.2021.678154

\author{
Xiang $\mathrm{Li}^{1 * t}$, Wenjun Wang ${ }^{1,2+}$, Jianghong Yan ${ }^{1}$ and Fancai Zeng ${ }^{1 *}$ \\ ${ }^{1}$ Department of Biochemistry and Molecular Biology, School of Basic Medical Science, Southwest Medical University, \\ Luzhou, China, ${ }^{2}$ Institute for Cancer Medicine and School of Basic Medical Sciences, Southwest Medical University, Luzhou, \\ China
}

Parkinson's disease (PD) is a common neurodegenerative disease in middle-aged and elderly individuals. At present, no effective drug has been developed to treat PD. Although a variety of drugs exist for the symptomatic treatment of PD, they all have strong side effects. Most studies on PD mainly focus on dopaminergic neurons. This review highlights the function of glutamic acid transporters (GLTs), including excitatory amino acid transporters (EAATs) and vesicular glutamate transporters (VGLUTs), during the development of PD. In addition, using bioinformatics, we compared the expression of different types of glutamate transporter genes in the cingulate gyrus of PD patients and healthy controls. More importantly, we suggest that the functional roles of glutamate transporters may prove beneficial in the treatment of PD. In summary, VGLUTs and EAATs may be potential targets in the treatment of PD. VGLUTs and EAATs can be used as clinical drug targets to achieve better efficacy. Through this review article, we hope to enable future researchers to improve the condition of PD patients.

Keywords: Parkinson's disease, excitatory amino acid transporters, vesicular glutamate transporters, glutamate, glutamic acid transporters

\section{INTRODUCTION}

Parkinson's disease (PD) is a common neurodegenerative disease characterized by resting tremor, bradykinesia, rigidity, and postural instability. Freezing of gait is a refractory symptom of PD, which is manifested by the short and sudden stop of the patient's step when he or she tries to walk or move forward. Freezing of gait, which is common in patients in the middle and late stages of PD, seriously affects the quality of life and prognosis of these patients. In addition, PD patients can also experience depression, olfactory dysfunction, sleep disorders, cognitive impairment, fatigue, and other non-motor symptoms (Kalia and Lang, 2015), which are common in early PD. The progression of PD is characterized by deterioration of motor function, which can initially be controlled by symptomatic treatment. However, as drug therapy continues, complications, such as dyskinesia and psychosis, may arise.

Parkinson's disease is the second most important age-related neurodegenerative disorder in developed societies, after Alzheimer's disease (AD). It is predicted that by 2030, approximately $3 \%$ of the global population over the age of 65 may be affected (Palakurthi and Burugupally, 2019). The main pathological feature of PD is the selective loss of dopaminergic neurons in the substantia nigra (SN) and the presence of Lewy bodies in the midbrain (Blauwendraat et al., 2020). The selective 
vulnerability of neurons in the $\mathrm{SN}$ is caused by several putative mechanisms, such as dopamine metabolism (da Silva et al., 2018), increased oxidative stress (Li et al., 2020b), iron accumulation (Xu et al., 2019; Bi et al., 2020; Lee et al., 2020), mitochondrial dysfunction (Park et al., 2020; Rani and Mondal, 2020), and dysregulation of the ubiquitin-proteasome system (Zheng et al., 2016). Another pathophysiological feature of PD is the loss of glutamatergic synapses and the increase in glutamatergic nerve transmission to the striatum (Raju et al., 2008). However, the pathogenesis of PD is not fully understood. The abnormal aggregation of $\alpha$-synuclein $(\alpha$-SYN), neuroinflammation, autophagy, tau hyperphosphorylation, and mitochondrial dysfunction have been reported to cause PD. The accumulation of $\alpha-S Y N$ to form Lewy bodies is considered to be the main pathogenic mechanism of PD. Studies have shown that the pathogenesis of $\mathrm{PD}$ is also related to glutamate (Glu) excitotoxicity (Chassain et al., 2010; Gibson et al., 2018). The excessive synthesis or release of Glu and the reduction in Glu reuptake lead to a high concentration of Glu in the synaptic space resulting in toxicity and neuronal death.

Glu is the major excitatory neurotransmitter in the mammalian central nervous system (CNS), where it participates in the physiological regulation of different processes. It has been demonstrated that excessive endogenous Glu is related to many chronic and acute neurodegenerative disorders such as epilepsy (Levite et al., 2020), amyotrophic lateral sclerosis (Mishra et al., 2016), cerebral ischemia (Wang et al., 2013), AD (Park et al., 2019), and PD (Tamano et al., 2019). Therefore, Glu excitotoxicity plays an important role in the development of PD. The subthalamic nucleus (STN) projects to the SN pars compacta $(\mathrm{SNpc})$ and $\mathrm{SN}$ pars reticulata (SNpr). The major cause of $\mathrm{PD}$ is the loss of dopaminergic neurons in the SNpc. Once these dopaminergic neurons are lost, calcium influx is induced by Glu release, which results in a cascade of reactions triggered by $\mathrm{Ca}^{2+}$ overload. Eventually, this process leads to degeneration and necrosis of dopaminergic neurons (Chu et al., 2017). At the same time, the reduced production of dopamine weakens the inhibition of STN and enhances the discharge of excitatory efferent neurons, which further aggravates Glu excitotoxicity (Blandini et al., 2000). Therefore, Glu neurotoxicity plays an important role in PD. To date, there are two main directions regarding the role of Glu in PD-Glu receptors and glutamic acid transporters (GLTs). Glu receptors, which are primarily located on postsynaptic and presynaptic neurons in almost all areas of the CNS, play a critical role in brain function. Pharmacologically, Glu receptors were originally classified into two major types-ionotropic Glu receptors (iGluRs) and metabotropic Glu receptors (mGluRs). iGluRs are multimeric ion channels that are responsible for fast excitatory transmission in the CNS. iGluRs transmit excitatory signals to postsynaptic neurons by binding to Glu released from presynaptic neurons. Glu can activate three types of iGluRs, namely, $\alpha$-amino-3-hydroxy-5-methyl-4-isoxazolepropionic acid (AMPA) receptors, $N$-methyl-D-aspartate (NMDA) receptors, and kainate receptors. mGluRs are members of the G-protein receptor superfamily; hence, they mediate the slow Glu responses, which contribute to long-lasting changes in synaptic activity (Schapira, 2010). According to their signal transduction mechanisms, pharmacology, and sequence homology, eight different types of mGluRs are classified into three groups (Group I: mGluR1 and mGluR5, Group II: mGluR2 and mGluR3, Group III: mGluR4, mGluR6, mGluR7, and mGluR8) (Menard and Quirion, 2012). In the pathophysiology of $\mathrm{PD}$, Glu receptors can undergo changes during the disease process, such as increased binding of Glu to NMDA receptors and decreased mGlu2/3 receptor expression, in monkeys (Jourdain et al., 2015). Many studies have shown that mGluRs and iGluRs play a critical role in MPTP-induced PD (Betarbet et al., 2000; Kintz et al., 2013; Al-Sweidi et al., 2016; Nuzzo et al., 2019; Mann et al., 2020). Therefore, some Glu receptor antagonists, such as amantadine (Hubsher et al., 2012) and memantine (Olivares et al., 2012), have been used as therapeutic drugs for PD. GLTs have been confirmed to have two types of transporters: excitatory amino acid transporters (EAATs) and vesicular Glu transporters (VGLUTs) (Wang et al., 2019). The level of extracellular Glu is regulated by highaffinity EAATs (Hayashi, 2018). EAATs maintain the dynamic equilibrium of the extracellular Glu concentration by protecting neurons from detrimental overstimulation of Glu receptors (Zerangue and Kavanaugh, 1996). EAATs can be divided into five subtypes: EAAT1, EAAT2, EAAT3, EAAT4, and EAAT5. In addition to the above mechanisms, VGLUT specifically transfers Glu into the synaptic vesicle, which determines the amount of Glu released into the synaptic cleft (Schenck et al., 2009). The VGLUT family presents distinct expression patterns. VGLUT1 and VGLUT2 are specifically expressed on glutamatergic neurons (El Mestikawy et al., 2011; Zhang et al., 2018a), while VGLUT3 usually acts as a cotransporter of Glu or other neurotransmitters, including gamma-aminobutyric acid (GABA), acetylcholine, and serotonin (El Mestikawy et al., 2011). Therefore, a comprehensive understanding of the role of Glu transporters in the pathophysiology of PD and as therapeutic targets will help in the development of new methods for the treatment of PD. In this review, we highlight the function of these different subtypes of Glu transporters and their potential neuroprotective effects, as well as evidence of the pharmacological manipulation of these transporters in PD.

\section{MOLECULAR MECHANISM OF GIU TRANSPORTERS IN PD}

Most studies have focused on the distribution, structure, and complex subunits of Glu receptors, as well as the functions of these receptors in PD. However, few studies have reported the role of EAATs and VGLUTs in regulating Glu concentration in PD.

\section{EAAT1}

High levels of extracellular Glu are associated with excitatory neuronal cell death. The best way to maintain the Glu concentration is to remove Glu from synapses by GLTs in astrocytes after pulsed transmission (Jia et al., 2015; Karki et al., 2015b). Upregulation of EAAT1 is related to improvements in 
neurological function after middle cerebral artery occlusion in rats (Matsuura et al., 2002; Mori et al., 2004). Some evidence indicates that EAAT1 functional upregulation can reduce neurotoxicity in related brain regions. Li et al. (2020a) showed that upregulation of EAAT1 may be a potential mechanism by which dopaminergic neurons are protected via reducing the toxicity of excitatory amino acids in a rodent model of PD. In addition, Chung et al. (2008) reported that reductions in EAAT1 can disrupt Glu homeostasis around glutamatergic synapses in the striatum and result in overspills of Glu in the CNS. This will eventually lead to damage of dopaminergic neurons. Astrocytes help to protect neurons through a variety of mechanisms, one of which is the uptake of Glu to prevent excitotoxicity (Sattler and Rothstein, 2006). Johnson et al. (2018) reported that regulation of EAAT1 protein and mRNA levels can result in resistance to manganese-induced neurotoxicity in mice. In other words, EAAT1 regulates the levels of Glu to resist neurotoxicity, including that which occurs in PD. Another study also showed that upregulating gene and protein expression levels of EAAT1 in cultured astrocytes could offer neuroprotection from excitotoxicity (Neal et al., 2018). Wu et al. (2019) found that upregulation EAAT1 triggers the Wnt signaling pathway and promotes dopaminergic neuron proliferation, thereby suppressing apoptosis in PD mice. In the acute MPTP (1-methyl-4-phenyl-1,2,3,6-tetrahydropyridine) mouse model and 6-hydroxydopamine (6-OHDA)-lesioned rat model of PD, decreased immunoreactivity and gene expression levels of EAAT1 are observed in the striatum (Holmer et al., 2005; El Arfani et al., 2015). Taken together, these data indicate that PD can lead to functional changes in astrocytes, which in turn lead to increased extracellular Glu through downregulation of the Glu transporter EAAT1, thereby damaging dopaminergic neurons and causing neurotoxicity. EAAT1 transports Glu from the synaptic cleft to maintain Glu homeostasis and prevent neuronal excitotoxicity (Figure 1A). Therefore, regulation of EAAT1 expression may be a potential therapeutic target in PD.

\section{EAAT2}

A series of studies has reported that EAAT2 is responsible for approximately $80 \%$ of total extracellular Glu uptake activities (Danbolt et al., 1992; Haugeto et al., 1996; Tanaka et al., 1997; Holmseth et al., 2012). Similar to EAAT1, EAAT2 is also primarily expressed in astrocytes. Reduced expression and function of EAAT2 have been reported in various neurodegenerative disorders, including AD and PD (Lin et al., 2012; Karki et al., 2015a). Many studies have reported that the Wnt signaling pathway can induce the EAAT2 expression (Palos et al., 1999; Parkin et al., 2018). A previous study showed that nuclear factor$\kappa \mathrm{B}(\mathrm{NF}-\kappa \mathrm{B})$ contributes to the neuron-dependent induction of EAAT2 expression (Ghosh et al., 2011). Many studies have shown that NF-кB is involved in the protective effects of the Wnt signaling pathway (Bournat et al., 2000; Shang et al., 2010). Moreover, Wei et al. (2019) demonstrated that Wnt regulates the EAAT2 level in astrocytes and protects dopaminergic cells against 6-OHDA toxicity. Zhang et al. (2018b) showed that ginsenoside could increase EAAT2 expression via NF-кB. Upregulation of EAAT2 can terminate Glu excitotoxicity and improve PD. These studies indicate that cross talk between the Wnt signaling pathway and the NF-кB pathway participates in the regulation of EAAT2 expression. Recently, many studies reported that the protein levels of EAAT2 in the striatum are decreased in animal models of PD according to immunofluorescence and western blot analyses, including in the 6-OHDA-lesioned PD model (Chung et al., 2008) and the MPTP-treated mouse model (Holmer et al., 2005). Chotibut et al. (2017) demonstrated that 1-3,4-dihydroxyphenylalanine (L-dopa)-induced dyskinesia severity is reduced when the expression of EAAT2 is increased in a rat 6-OHDA model of PD. Zhang et al. (2020) found that EAAT2 deficiency in the SN induces a PD phenotype according to progressive motor deficits and the death of nigral dopaminergic neurons in mice. Singh et al. (2018) found that acetyl-L-carnitine could reduce the accumulation of ROS and promote the expression of EAAT2 to protect neurons. In addition, acetyl-L-carnitine treatment protects DA neurons, thus preserving the integrity of the nigrostriatal pathway, which may result in improvement in PD. Ceftriaxone can increase EAAT2 expression and decrease Glu content to protect neurons. In addition, Leung et al. (2012) demonstrated that the side chain of ceftriaxone, $\mathrm{D}$ - $\alpha$-aminoadipic acid, is readily carbonylated upon oxidative damage and prevents the carbonylation of endogenous target, thereby protecting neurons (Tikka et al., 2001). All these studies suggest that EAAT2 is an important target for the treatment of PD. EAAT2 transports Glu from the synaptic cleft to maintain Glu homeostasis and prevent neuronal excitotoxicity (Figure 1A). Therefore, some well-known drugs protect dopaminergic neurons by upregulating the expression of EAAT2, which is an important mechanism for the treatment and prevention of PD.

\section{EAAT3}

EAAT3 is primarily expressed in neurons, especially at postsynaptic terminals (He and Casaccia-Bonnefil, 2008). Even though EAAT3 is expressed in all CNS neurons (Rothstein et al., 1994; Shashidharan et al., 1997), growing evidence indicates that EAAT3 expression is particularly dense on SN dopaminergic neurons (Nafia et al., 2008; Berman et al., 2011). Aoyama found that EAAT3 is involved in MPTP-induced glutathione depletion and motor dysfunction (Aoyama et al., 2008). In addition to Glu, EAAT3 also mediates the transport of cysteine (Cys) in neurons (Hayes et al., 2005), where it provides a Cys substrate for the synthesis of glutathione (GSH). Consistent with this view, EAAT3 inhibition leads to GSH loss and subsequent cell death of dopaminergic neurons in mice and rats (Nafia et al., 2008). Therefore, deletion of EAAT3 in mice impairs neuronal Cys uptake, which results in chronic neuronal oxidative stress. Berman et al. (2011) suggested that oral N-acetylcysteine could restore reactive thiol content in EAAT3 knockout dopaminergic neurons. In addition to transporting Glu and Cys, EAAT3 also plays an important role in regulating GABA $(\gamma$-aminobutyric acid) synthesis (Sepkuty et al., 2002), reducing oxidative stress in neurons (Yang et al., 2018), and supporting neuron viability (Duerson et al., 2009). Downregulation of EAAT3 expression through antisense RNA approaches increases the sensitivity of neurons to excitotoxic injury (Brustovetsky et al., 2004) and 

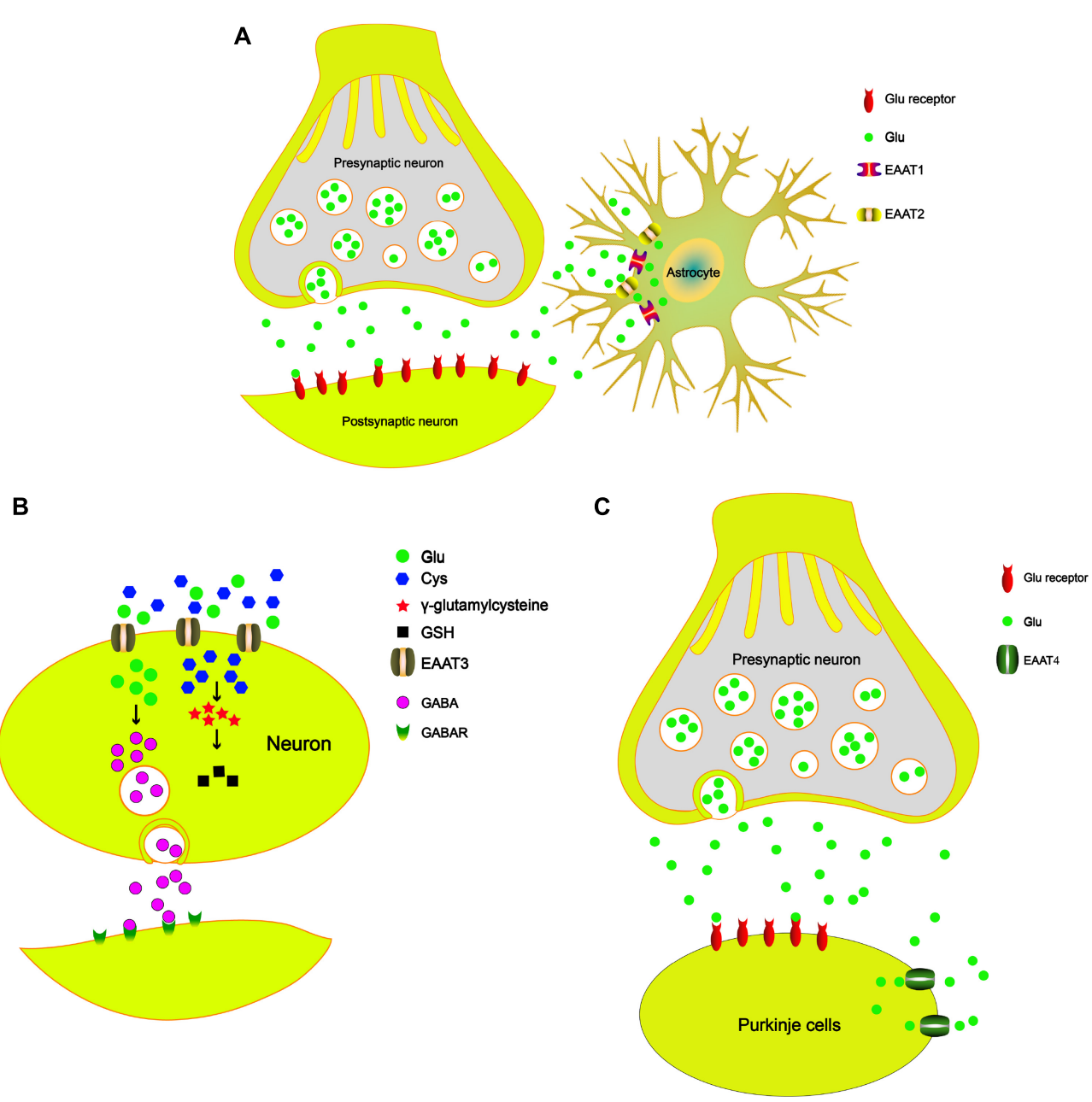

FIGURE 1 | The role of EAATS in the PD model. (A) The tripartite synapse is composed of the presynaptic neuron, postsynaptic neuron, and astrocytes. EAAT1 and EAAT2 uptake Glu from the synaptic cleft to maintain Glu homeostasis and prevent the excitotoxicity of neurons. (B) EAAT3 uptakes Cys and then synthesizes GSH, which reduces oxidative damage. EAAT3 modulates GABA synthesis and maintains GABA homeostasis. (C) EAAT4 plays a key role in the synaptic activity of cerebellar Purkinje cells by regulating extracellular Glu concentrations.

causes dendritic swelling in the hippocampus (Rothstein et al., 1996). More importantly, recent studies have indicated that EAAT3 deficiency leads to neuronal loss (Aoyama et al., 2006), which shows that EAAT3 is essential to the viability of supporting neurons. Increasing evidence suggests that EAAT3 can modulate GABA synthesis (Mathews and Diamond, 2003) and that the levels of GABA are crucial to PD development (Blaszczyk, 2016; Firbank et al., 2018; Liu et al., 2019). These results support the view that EAAT3 dysfunction can lead to a range of damaging neuropathological consequences, including decreased GABA synthesis, increased susceptibility to oxidative neuronal injury, decreased Glu clearance, and ultimately neuronal loss. Exercise can alleviate locomotor impairment in PD. Arnold and Salvatore (2016) demonstrated that the expression of EAAT3 and tyrosine hydroxylase (TH) is increased after short-term exercise. Together, these findings suggest an important role for EAAT3 in dopaminergic neuronal GSH metabolism and a contributory role for GSH depletion in dopaminergic neuronal death. In addition, EAAT3 also influences the levels of GABA, which affects the development of parkinsonian symptoms. In summary, EAAT3 can transport Cys and synthesize GSH, which reduces oxidative damage. EAAT3 can modulate GABA synthesis and maintain GABA homeostasis, which has an important role in the development of PD (Figure 1B).

\section{EAAT4}

EAAT4 is a member of the high-affinity $\mathrm{Na}^{+} / \mathrm{K}^{+}$-dependent Glu transporter family and is mainly expressed in Purkinje cells of the cerebellum (Massie et al., 2008). EAAT4 plays a key role in the synaptic activity of cerebellar Purkinje cells by regulating extracellular Glu concentrations (Jiang et al., 2016). Takada et al. (1993) reported that neuronal degeneration induced by MPTP occurs in the cerebellum and is characterized by the loss of Nissl-stained Purkinje cells. The STN projects to the cerebellum likely by way of the pontine nuclei (PN) (Bostan and Strick, 2018), and the projection from the PN to the cerebellum 
consists of glutamatergic neurons (Beitz et al., 1986). A previous study suggested that midbrain dopaminergic neurons affect glutamatergic transmission in the cerebellum, which may be important for the generation of the tremors (Golembiowska et al., 2013). In a rat model of PD induced by the intrastriatal injection of rotenone, the concentration of Glu in the cerebellum is significantly increased (Khadrawy et al., 2017). In addition, Zhou et al. (2018) reported that miR-128 overexpression contributes to EAAT4 upregulation and protects dopaminergic neurons from apoptosis, thereby alleviating PD in mice. Therefore, according to current research, Glu neurotransmitters should be considered during the treatment of PD. To our knowledge, the roles of the cerebellum in PD remain limited, and further focus on the cerebellum should be centered on Glu transporters, especially EAAT4. In summary, we propose that in Purkinje cells of the cerebellum, EAAT4 influences the development of parkinsonian symptoms (such as bradykinesia, rigidity, and tremor) by regulating the Glu concentration (Figure 1C).

\section{EAAT5}

EAAT5 is primarily expressed in bipolar cells, photoreceptors, and amacrine cells. EAAT5 is a well-known chloride channel activated by Glu that controls the excitability of retinal neurons (Picaud et al., 1995; Arriza et al., 1997; Eliasof et al., 1998; Pow and Barnett, 2000; Wersinger et al., 2006). EAAT5 has the largest chloride conductance than the other types of EAATs, and its function is more as an inhibitory Glu receptor than as a transporter (Zhou and Danbolt, 2013). The physiological role of EAAT5 is not fully understood, but its low Glu transport rate and Glu affinity argue against a major role in Glu reuptake, and EAAT5 is always considered a Glu-gated anion channel. To date, no animal models deficient in EAAT5 have been reported, and no disease has been linked to gene mutations in EAAT5 in humans. Therefore, the development of these models may enable us to clearly identify the cellular function of EAAT5. The particularity of EAAT5 may be one reason for the lack of reports that describe a relationship between EAAT5 and PD.

\section{VGLUT1}

Vesicular glutamate transporters are located in the membrane of presynaptic glutamatergic synaptic vesicles and are responsible for loading Glu into vesicles (Figure 2A). Then, the vesicles fuse with the presynaptic membrane and releases Glu into the synaptic cleft (Massie et al., 2010). Since the number of VGLUT molecules in each synaptic vesicle plays an important role in the quantal size of glutamatergic neurons, changes in VGLUT expression may have a significant impact on synaptic transmission (Wojcik et al., 2004). The expression of VGLUTs is an indicator of the relative synaptic strength of presynaptic glutamatergic innervation in specific brain regions (Massie et al., 2010). Therefore, VGLUTs play an important role in neurodegenerative diseases (Daniels et al., 2011; Steinkellner et al., 2018; Ibrahim et al., 2020). VGLUT1 is one of the specific markers of glutamatergic neurons. A series of studies has shown that VGLUT1 is expressed in the hippocampus, thalamus, cerebral, cerebellar cortices, amygdala, and cerebellum (Ni et al., 1995; Bellocchio et al., 1998; Herzog et al., 2001; Lee et al., 2015; Fattorini et al., 2017;
Fang et al., 2018). Many studies have shown that the protein expression of VGLUT1 is reduced in the prefrontal cortex (PFC) of PD patients compared with control subjects (Kashani et al., 2007; Granseth et al., 2015). However, Raju et al. (2008) found that the total density of VGLUT1 is significantly increased in the striatum of MPTP-treated parkinsonian monkeys. In addition, postmortem human data also support the view that VGLUT1 expression is increased in the striatum of PD patients (Kashani et al., 2007). A previous study found that complete knockout of VGLUT1 leads to postnatal lethality in C57BL/6 mice and that heterozygous mice show impaired hippocampal long-term potentiation (LTP) accompanied by a deficit in spatial reversal learning (Balschun et al., 2010). Fremeau et al. (2004) showed that synaptic vesicle-enriched membrane fractions from VGLUT1I- mice also exhibit a reduction in Glu. Deletion of VGLUT most likely alters the probability of Glu release from nerve endings. Clinically, the STN is an important target of deep brain electrical stimulation in the treatment of PD. Wang showed that electroacupuncture treatment restores the downregulation of VGLUT1 in the STN in a model of PD induced by 6-OHDA (Wang et al., 2018). Electroacupuncture can reduce the motor symptoms of PD by upregulating VGLUT1 expression in the STN, which suggests that upregulation of VGLUT1 in the STN improves dyskinesia in PD through the cortico-STN pathway (Massie et al., 2010). In summary, the abnormal transmission of Glu in PD can result in disease-related motor and cognitive disorders. Increasing evidence suggests that changes in VGLUT1 protein expression are involved in the progression of $\mathrm{PD}$.

\section{VGLUT2}

Damage to DA neurons is the major cause of PD. TH is the rate-limiting enzyme in dopamine synthesis and is a marker of dopamine. Recent studies have shown that VGLUT2 and TH are coexpressed in the striatum of rats and mice (Berube-Carriere et al., 2009; Chuhma et al., 2009; Trudeau et al., 2014; Morales and Margolis, 2017). VGLUT2 is a major subtype of VGLUTs expressed in midbrain dopaminergic neurons (Morales and Root, 2014) and is responsible for loading Glu into vesicles (Figure 2A). A previous study showed that selective knockout of VGLUT2 can significantly reduce the expression of the brain-derived neurotrophic factor (BDNF) and its receptor tyrosine receptor kinase B (TrkB), which results in significant DA neuron death induced by MPTP. Rescuing the expression of VGLUT2 in DA neurons reverses these alterations (Shen et al., 2018). Steinkellner also demonstrated that overexpression of VGLUT2 is sensitive to DA neurons and that endogenous VGLUT2 deletion increases the susceptibility of DA neurons to parkinsonian neurotoxins in mice (Steinkellner et al., 2018). DA neuron loss in the SN in PD leads to overactivation of the STN. Moreover, VGLUT2 is localized in STN terminals synapsing within the SN (Moore et al., 2020). Several studies have demonstrated that VGLUT2 expression in DA neurons is necessary for normal emotional responses and psychostimulant-mediated behavioral activation (Birgner et al., 2010). In addition, a series of studies has suggested that the reduced expression levels of VGLUT2 in the STN of mice cause degeneration of midbrain DA neurons (Schweizer et al., 2014, 2016; Moore et al., 2020). Another study found 

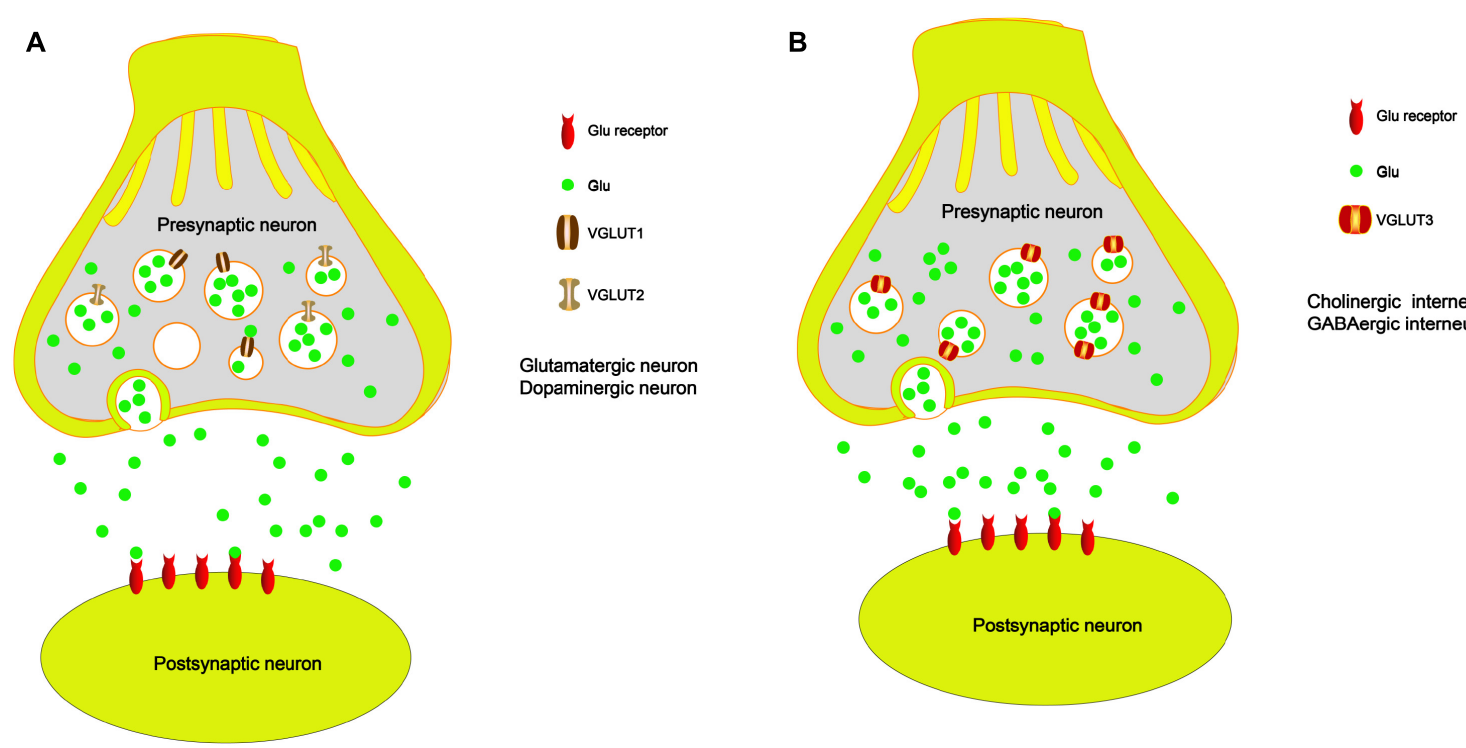

Cholinergic interneuron GABAergic interneurons

FIGURE 2 | The role of VGLUTs in the PD model. (A) VGLUT1 and VGLUT2 load Glu into vesicles, and they fuse with the presynaptic membrane and release Glu into the synaptic cleft, especially in the glutamatergic neurons and dopaminergic neurons. (B) VGLUT3 loads Glu into vesicles, and it fuses with the presynaptic membrane and releases Glu into the synaptic cleft, especially in the cholinergic neurons and GABAergic neurons.

that MPTP injected into mice induces a decrease in VGLUT2 expression in the striatum compared with the control group (Pflibsen et al., 2015). In other words, we suggest that VGLUT2 trafficking to sites of somatodendritic DA release may cause the activation of presynaptic Glu receptors on DA neurons, which results in excitotoxicity. These results indicated that enhanced Glu release induced by the reduced expression of VGLUT2 results in further DA neuron death. Therefore, regulating the expression of VGLUT2 in DA neurons may be an important factor in the development of PD and suggests a potential therapeutic strategy by activating DA neurons.

\section{VGLUT3}

VGLUT3 is expressed in non-glutamatergic neurons, including cholinergic striatal interneurons, and GABAergic interneurons, which are responsible for loading Glu into vesicles (Figure 2B). VGLUT3 can also regulate DA signaling and movement activity. Therefore, VGLUT3 affects the activity of DA neurons by regulating the concentration of Glu neurotransmitters. It has been reported that VGLUT3 knockout mice exhibit hyperlocomotion (Gras et al., 2008), which is related to increased midbrain DA signaling. Divito found that deletion of VGLUT3 results in upregulation of the midbrain dopamine system in mice. The KO mice show less abnormal motor behavior after 6-OHDA administration; however, the mice present fewer abnormal dyskinesias in response to L-dopa-induced dyskinesia (Divito et al., 2015). Another study also showed that DA depletion in the striatum increases the expression levels of VGLUT3. This is mainly because the inhibitory effect of Glu on DA release is weakened. The authors also suggest that VGLUT3 plays a key role in the development of L-dopa-induced dyskinesia (Gangarossa et al., 2016). At present, few studies have demonstrated the critical role of VGLUT3 in PD. Most studies have found that VGLUT3 plays a crucial role in levodopa-induced dyskinesia, which occurs in patients with PD who have been treated with levodopa over a long period of time.

\section{DISCUSSION}

Parkinson's disease is a typical neurodegenerative disease, the pathogenesis of which is complex. Previous studies have shown that Glu excitotoxicity may result in the loss of SN dopaminergic neurons (Wang et al., 2020). In PD patients, Glu excitotoxicity decreases dopaminergic neuronal transmission, while glutamatergic neurons in the basal ganglia can stimulate dopaminergic neurons in the $\mathrm{SN}$ to release DA as a compensatory mechanism. However, excessive activation may be lethal to dopaminergic neurons and even cause the death of these neurons (Blandini et al., 2000). No effective drug can prevent or treat PD. Judging from the current study, most drug targets mainly focus on the dopaminergic neuron system and are either dopamine replacements or dopamine receptor stimulants. Common drugs used to treat PD are classified according to their different targets, as shown in Table 1. Although various types of drugs help patients effectively alleviate Parkinson's-like symptoms, these drugs are associated with many side effects (for example, alimentary symptoms, postural hypotension, insomnia, and dyskinesia). Currently, no drugs target EAATs or VGLUTs in the treatment of PD. Therefore, the development of Glu transporters as novel drug targets for the treatment of $\mathrm{PD}$ is very promising.

Other neurological disorders, such as ataxia, may be relevant to the pathology of PD. An increasing body of evidence suggests that mutation in EAAT1 results in decreased uptake of Glu, which 
TABLE 1 | Classification of common drugs for the treatment of PD.

\begin{tabular}{|c|c|c|c|}
\hline Type & Target & Drug & References \\
\hline Dopamine replacers & Dopamine neurons & L-DOPA & Armstrong and Okun, 2020 \\
\hline \multirow[t]{5}{*}{ Antagonists } & $N$-methyl-D-aspartic acid & Amantadine & Hubsher et al., 2012 \\
\hline & receptor (NMDAR) & Menantine & Olivares et al., 2012 \\
\hline & & Riluzole & Liu and Wang, 2018 \\
\hline & Adenosine A2A Receptor & Istradefylline & Muller, 2015 \\
\hline & & Tozadenant & Oertel and Schulz, 2016 \\
\hline \multirow[t]{6}{*}{ Agonists } & Dopamine receptors & Apomorphine & Boyle and Ondo, 2015 \\
\hline & & Pramipexole & Frampton, 2014 \\
\hline & & Ropinirole & Matheson and Spencer, 2000 \\
\hline & & Piribedil & Perez-Lloret and Rascol, 2016 \\
\hline & Serotonin receptors & F15599 & Iderberg et al., 2015 \\
\hline & & Pimavanserin & Sahli and Tarazi, 2018 \\
\hline \multirow[t]{6}{*}{ Inhibitor } & Monoamine oxidase-B & Selegiline & Szoko et al., 2018 \\
\hline & & Rasagiline & (Szoko et al., 2018 \\
\hline & Catechol-O-methyltransferase & Tolcapone & Keating and Lyseng-Williamson, 2005 \\
\hline & & Entacapone & Schrag, 2005) \\
\hline & Cholinergic neurons & Trihexyphenidyl & Takahashi et al., 1999 \\
\hline & & Benzatropine & Agundez et al., 2013 \\
\hline
\end{tabular}

can cause hemiplegia, migraine, ataxia, and epilepsy (Jen et al., 2005; Stacey et al., 2010; Parinejad et al., 2016). In addition, in ataxia, inactivation of EAAT4 impairs spontaneous activity of Purkinje cells, which causes neuronal death (Serra et al., 2004; Perkins et al., 2010). One study showed that upregulation of EAAT4 can protect dopaminergic neurons from apoptosis, thereby alleviating PD in mice (Zhou et al., 2018). Sanjay et al. suggested that regional reductions in EAAT2-4 expression could induce increased Glu levels, which may be associated with human epilepsy (Rakhade and Loeb, 2008). Therefore, EAAT-associated anion channels may play an important role in many neurodegenerative diseases such as PD, ataxia, and epilepsy. However, the specific mechanisms remained unclear. Dopaminergic neuron death induced by oxidative stress played an important factor in PD. In addition, some EAATs act as chloride channels or mediate the uptake of Cys, which can produce the ROS scavenger GSH (Lim et al., 2005; Aoyama and Nakaki, 2013; Robert et al., 2014). EAAT also functions as an anion channel, which plays an important role in the regulation of glial cells in the CNS (Untiet et al., 2017), especially in the apoptosis of glial cells induced by ataxia (Kovermann et al., 2020). Therefore, we suggest that EAAT may have the same effect in PD. The expression levels of VGLUTs, with the exception of EAATs, determine the amount of Glu loaded into vesicles and released, thus regulating the effect of neurotransmission (Wojcik et al., 2004). Therefore, changes in the expression of VGLUTs may have a significant impact on synaptic transmission and may ultimately affect neurons. Kashani et al. (2007) suggested that the downregulation of VGLUT1 in the PFC is associated with cognitive dysfunction in PD. The mechanism may be that the level of VGLUT1 can directly affect presynaptic quantal size, which supports the possibility that increased expression of VGLUT1 can enhance corticostriatal neuron signaling (Wojcik et al., 2004; Wilson et al., 2005); this may serve as an adaptive mechanism to compensate for the loss of dopaminergic neurons. In addition, upregulation of VGLUT2 dopaminergic neurons can promote Glu release, which drives axonal outgrowth and results in dopaminergic neuron axonal plasticity in the postlesional brain (Kouwenhoven et al., 2020). We suggest that this increase promotes the survival of dopaminergic neurons. A previous study showed that deletion of VGLUT3 not only abolishes the Glu signaling (Higley et al., 2011) but also significantly reduces cholinergic transmission (Nelson et al., 2014). Therefore, these results showed that VGLUTs may play an important role in the treatment of PD by regulating the levels of acetylcholine and Glu. In addition, Daniels et al. (2006) found only one VGLUT per synaptic vesicle. In other words, upregulation of VGLUT can result in the addition of another transporter and an increase in quantal size, while downregulation of VGLUT leads to a mix of vesicles or no transporter and empty vesicles. In this way, VGLUT may be important for vesicle recycling and the rapid regulation of Glu concentration.

Glu is also the major excitatory neurotransmitter in the basal ganglia, which is the site of dyskinesia in PD (Greenamyre et al., 1994). Some studies have reported that high levels of Glu in the brain lead to increased accumulation of reactive oxygen species (ROS), which leads to an imbalance in intracellular redox. In other words, ROS induced by Glu excitotoxicity play an important role in the development of PD (Son et al., 2013; Buchanan et al., 2015). Therefore, regulating the concentration of Glu in the brain may be a potential treatment for PD and recent studies have focused on the role of Glu receptors in PD. However, few studies on the role of EAATs and VGLUTs in $\mathrm{PD}$ have been published. In this review, we report that different types of EAATs and VGLUTs are located in different types of neurons, including dopaminergic neurons, glutamatergic neurons, cholinergic neurons, and GABAergic neurons. With the exception of EAAT5, many studies have reported that 
Glu transporters play an important role in the course of PD development. Increasing evidence suggests that dysregulation of the glutamatergic nervous system is one of the major reasons for disease and that these disorders accelerate disease progression. Studies on the mechanism of Glu transporters in the pathological changes of neuronal synapses, synaptic plasticity, filling size, and transport velocity of synaptic vesicles are inadequate. Regulating the function of EAATs and VGLUTs to promote neuroprotection may be an effective intervention and treatment strategy for the treatment of PD. In addition, we examined the expression of Glu transporters in the cingulate gyrus of eight patients with PD and eight control subjects. The cingulate gyrus, a region in which $\alpha-S Y N$ accumulates, is a key node of the neural network, which includes the amygdala, the ventral striatum, and the SN,
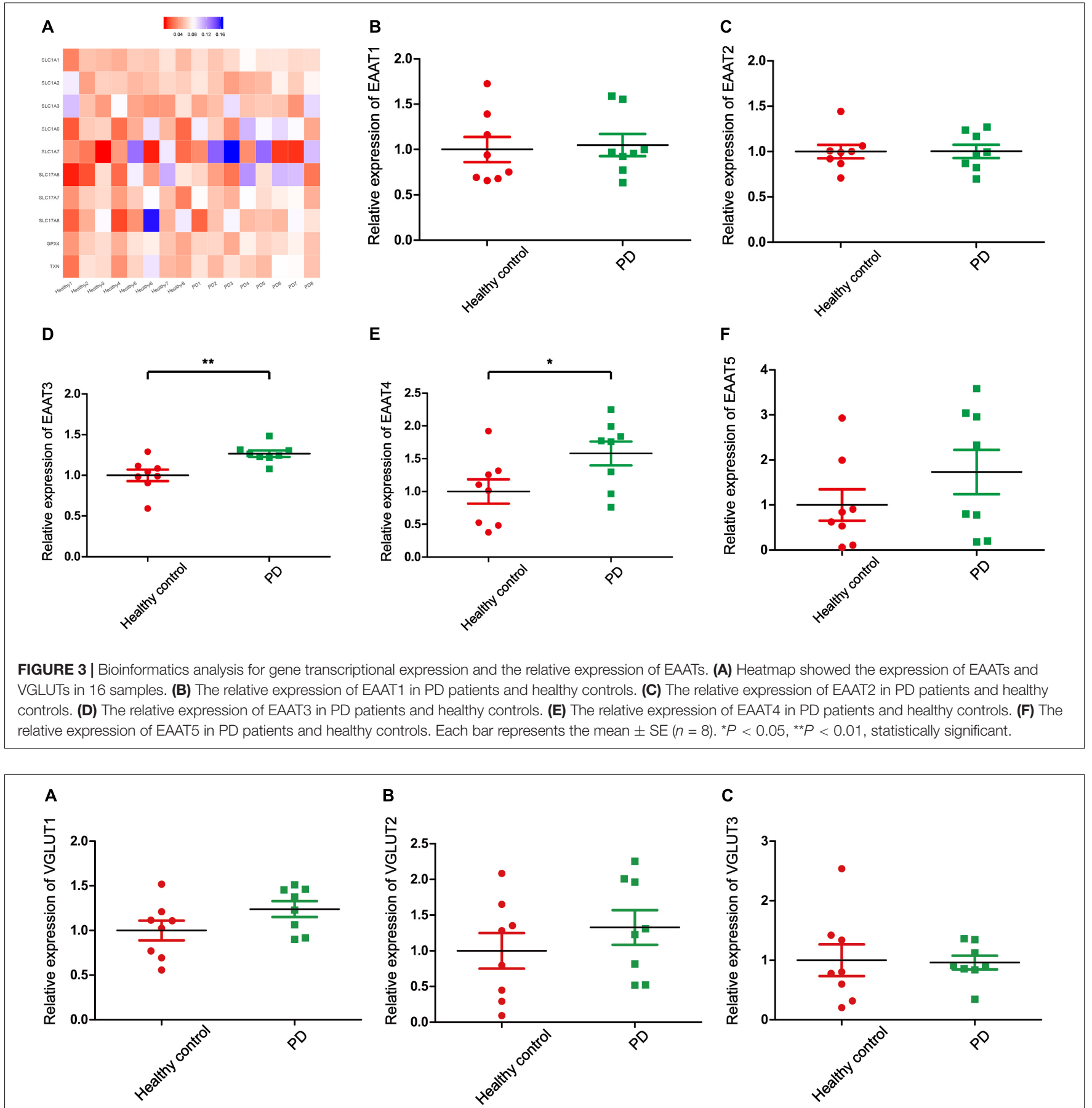

FIGURE 4 | The relative expression of VGLUTs. (A) The relative expression of VGLUT1 in PD patients and healthy controls. (B) The relative expression of VGLUT2 in PD patients and healthy controls. (C) The relative expression of VGLUT3 in PD patients and healthy controls. Each bar represents the mean \pm SE $(n=8)$. 
and is related to cognitive impairment (Bressler and Menon, 2010). In addition, L-6-18F-fluoro-3,4-dihydroxyphenylalanine (FDOPA) PET has been widely used to quantify dopamine metabolism in the clinic. This method is used to evaluate the ability of neurons in the SN to synthesize dopamine. The cingulate gyrus, which receives dopaminergic projections from the ventral tegmental area through the mesolimbic pathway, is the region of highest FDOPA uptake among frontal cortical regions (Kumakura et al., 2010; Blanchet and Brefel-Courbon, 2018). Therefore, exploring Glu transporters in the cingulate gyrus may be important in the early clinical diagnosis and treatment of PD. We used transcriptome datasets downloaded from NCBI (GSE110716). Heatmap showed the expression of EAATs and VGLUTs (Figure 3A). We found that the expression levels of EAAT3 and EAAT4 are upregulated in patients compared with control subjects in Figures 3D,E. In contrast, the other types of Glu transporters are not altered (Figures 3B,C,F, 4). In patients with $\mathrm{PD}$, the increased levels of EAAT3 and EAAT4 may be a protective mechanism that alleviates PD symptoms. The other types of Glu transporters exhibit no significant changes, which may be due to the following reasons: 1 . The number of human samples is too small. 2. The expression of Glu transporters may vary according to brain region. Importantly, we found that in human patients with PD, Parkinson's symptoms may be alleviated by increasing the expression of Glu transporters.

Currently, an increase in the understanding of the function of Glu receptors in the nervous system is highly warranted. Future studies should include the following areas of research: upregulating or interfering with the expression of $\mathrm{Glu}$ transporters in different brain regions in a PD model, detecting the role of Glu transporter agonists or inhibitors in a PD model, and assessing the combined effects of different types of Glu transporters in a PD model and the combined effects of Glu transporters and other PD targets in a PD model. Although many studies have demonstrated that abnormal levels of Glu transporters may be one of the causes of various mental disorders, the origins of these complex disorders are not yet fully understood. Further understanding of the function of EAATs

\section{REFERENCES}

Agundez, J. A., Garcia-Martin, E., Alonso-Navarro, H., and Jimenez-Jimenez, F. J. (2013). Anti-Parkinson's disease drugs and pharmacogenetic considerations. Expert Opin. Drug Metab. Toxicol. 9, 859-874. doi: 10.1517/17425255.2013. 789018

Al-Sweidi, S., Morissette, M., and Di Paolo, T. (2016). Estrogen receptors modulate striatal metabotropic receptor type 5 in intact and MPTP male mice model of Parkinson's disease. J. Steroid. Biochem. Mol. Biol. 161, 84-91. doi: 10.1016/j. jsbmb.2016.02.004

Aoyama, K., Matsumura, N., Watabe, M., and Nakaki, T. (2008). Oxidative stress on EAAC1 is involved in MPTP-induced glutathione depletion and motor dysfunction. Eur. J. Neurosci. 27, 20-30. doi: 10.1111/j.1460-9568.2007. 05979.x

Aoyama, K., and Nakaki, T. (2013). Neuroprotective properties of the excitatory amino acid carrier 1 (EAAC1). Amino Acids 45, 133-142. doi: 10.1007/s00726013-1481- 1485

Aoyama, K., Suh, S. W., Hamby, A. M., Liu, J., Chan, W. Y., Chen, Y., et al. (2006). Neuronal glutathione deficiency and age-dependent neurodegeneration in the EAAC1 deficient mouse. Nat. Neurosci. 9, 119-126. doi: 10.1038/nn1609 and VGLUTs may also prove highly beneficial to elucidating the mechanisms of PD and other nervous system diseases. In the future, we hope to improve the condition of PD patients.

\section{CONCLUSION}

In this review, we highlighted the potential roles of EAATs and VGLUTs in the treatment of PD. With the exception of EAAT5, Glu transporters have significant functions in regulating the levels of Glu, DA, and GABA. Many studies have shown that Glu transporters can improve excitatory toxicity in neurons by regulating the activities of dopaminergic neurons, glutamatergic neurons, and GABAergic neurons in the development of PD. In addition, by regulating the expression of Glu transporters, the levels of ROS in neurons can be affected. The accumulation of ROS is an important cause of PD. Therefore, we propose that EAATs and VGLUTs should be important components in the study of PD. We should therefore study these transporters as they relate to $\mathrm{PD}$ and by doing so improve the lives of patients with PD.

\section{AUTHOR CONTRIBUTIONS}

$\mathrm{XL}$ and FZ were responsible for the study concept and design and provided a critical revision of the manuscript for important intellectual content. WW and JY drafted the manuscript. All the authors read and approved the final version.

\section{FUNDING}

This study was financially supported by grants from the Science and Technology Strategic Cooperation Project of the Luzhou People's Government and Southwest Medical University (No. 2019LZXNYDJ34) and the undergraduate innovation and entrepreneurship training program (S202010632282).

Armstrong, M. J., and Okun, M. S. (2020). Diagnosis and treatment of parkinson disease: a review. JAMA 323, 548-560. doi: 10.1001/jama.2019.22360

Arnold, J. C., and Salvatore, M. F. (2016). Exercise-Mediated increase in nigral tyrosine hydroxylase is accompanied by increased nigral GFR-alphal and EAAC1 expression in aging rats. ACS Chem. Neurosci. 7, 227-239. doi: 10.1021/ acschemneuro.5b00282

Arriza, J. L., Eliasof, S., Kavanaugh, M. P., and Amara, S. G. (1997). Excitatory amino acid transporter 5 , a retinal glutamate transporter coupled to a chloride conductance. Proc. Natl. Acad. Sci. U S A. 94, 4155-4160. doi: 10.1073/pnas.94. 8.4155

Balschun, D., Moechars, D., Callaerts-Vegh, Z., Vermaercke, B., Van Acker, N., Andries, L., et al. (2010). Vesicular glutamate transporter VGLUT1 has a role in hippocampal long-term potentiation and spatial reversal learning. Cereb. Cortex 20, 684-693. doi: 10.1093/cercor/bhp133

Beitz, A. J., Larson, A. A., Monaghan, P., Altschuler, R. A., Mullett, M. M., and Madl, J. E. (1986). Immunohistochemical localization of glutamate, glutaminase and aspartate aminotransferase in neurons of the pontine nuclei of the rat. Neuroscience 17, 741-753. doi: 10.1016/0306-4522(86)90042-90044

Bellocchio, E. E., Hu, H., Pohorille, A., Chan, J., Pickel, V. M., and Edwards, R. H. (1998). The localization of the brain-specific inorganic phosphate transporter 
suggests a specific presynaptic role in glutamatergic transmission. J. Neurosci. 18, 8648-8659.

Berman, A. E., Chan, W. Y., Brennan, A. M., Reyes, R. C., Adler, B. L., Suh, S. W., et al. (2011). N-acetylcysteine prevents loss of dopaminergic neurons in the EAAC1-/- mouse. Ann. Neurol. 69, 509-520. doi: 10.1002/ana.22162

Berube-Carriere, N., Riad, M., Dal, Bo, G., Levesque, D., Trudeau, L. E., et al. (2009). The dual dopamine-glutamate phenotype of growing mesencephalic neurons regresses in mature rat brain. J. Comp. Neurol. 517, 873-891. doi: $10.1002 / \mathrm{cne} .22194$

Betarbet, R., Porter, R. H., and Greenamyre, J. T. (2000). GluR1 glutamate receptor subunit is regulated differentially in the primate basal ganglia following nigrostriatal dopamine denervation. J. Neurochem. 74, 1166-1174. doi: 10.1046/ j.1471-4159.2000.741166.x

Bi, M., Du, X., Jiao, Q., Liu, Z., and Jiang, H. (2020). alpha-Synuclein regulates iron homeostasis via preventing parkin-mediated DMT1 ubiquitylation in Parkinson's disease models. ACS Chem. Neurosci. 11, 1682-1691. doi: 10.1021/ acschemneuro.0c00196

Birgner, C., Nordenankar, K., Lundblad, M., Mendez, J. A., Smith, C., le Greves, M., et al. (2010). VGLUT2 in dopamine neurons is required for psychostimulantinduced behavioral activation. Proc. Natl. Acad. Sci. U S A. 107, 389-394. doi: 10.1073/pnas.0910986107

Blanchet, P. J., and Brefel-Courbon, C. (2018). Chronic pain and pain processing in Parkinson's disease. Prog. Neuropsychopharmacol. Biol. Psychiatry 87(Pt B), 200-206. doi: 10.1016/j.pnpbp.2017.10.010

Blandini, F., Nappi, G., Tassorelli, C., and Martignoni, E. (2000). Functional changes of the basal ganglia circuitry in Parkinson's disease. Prog. Neurobiol. 62, 63-88. doi: 10.1016/s0301-0082(99)00067-62

Blaszczyk, J. W. (2016). Parkinson's disease and neurodegeneration: GABAcollapse hypothesis. Front. Neurosci. 10:269. doi: 10.3389/fnins.2016.00269

Blauwendraat, C., Nalls, M. A., and Singleton, A. B. (2020). The genetic architecture of Parkinson's disease. Lancet Neurol. 19, 170-178. doi: 10.1016/S1474-4422(19) 30287-X

Bostan, A. C., and Strick, P. L. (2018). The basal ganglia and the cerebellum: nodes in an integrated network. Nat. Rev. Neurosci. 19, 338-350. doi: 10.1038/s41583018-0002-7

Bournat, J. C., Brown, A. M., and Soler, A. P. (2000). Wnt-1 dependent activation of the survival factor NF-kappaB in PC12 cells. J. Neurosci. Res. 61, 21-32.

Boyle, A., and Ondo, W. (2015). Role of apomorphine in the treatment of Parkinson's disease. CNS Drugs 29, 83-89. doi: 10.1007/s40263-014-0221-z

Bressler, S. L., and Menon, V. (2010). Large-scale brain networks in cognition: emerging methods and principles. Trends Cogn. Sci. 14, 277-290. doi: 10.1016/ j.tics.2010.04.004

Brustovetsky, T., Purl, K., Young, A., Shimizu, K., and Dubinsky, J. M. (2004). Dearth of glutamate transporters contributes to striatal excitotoxicity. Exp. Neurol. 189, 222-230. doi: 10.1016/j.expneurol.2004.03.021

Buchanan, R. J., Gjini, K., Darrow, D., Varga, G., Robinson, J. L., and Nadasdy, Z. (2015). Glutamate and GABA concentration changes in the globus pallidus internus of Parkinson's patients during performance of implicit and declarative memory tasks: a report of two subjects. Neurosci. Lett. 589, 73-78. doi: 10.1016/ j.neulet.2015.01.028

Chassain, C., Bielicki, G., Durand, E., Lolignier, S., Essafi, F., Traor, A., et al. (2010). Metabolic changes detected by proton magnetic resonance spectroscopy in vivo and in vitro in a murin model of Parkinson's disease, the MPTP-intoxicated mouse. J. Neurochem. 105, 874-882.

Chotibut, T., Meadows, S., Kasanga, E. A., McInnis, T., Cantu, M. A., Bishop, C., et al. (2017). Ceftriaxone reduces L-dopa-induced dyskinesia severity in 6-hydroxydopamine parkinson's disease model. Mov. Disord. 32, 1547-1556. doi: $10.1002 / \mathrm{mds} .27077$

Chu, H. Y., McIver, E. L., Kovaleski, R. F., Atherton, J. F., and Bevan, M. D. (2017). Loss of hyperdirect pathway cortico-subthalamic inputs following degeneration of midbrain dopamine neurons. Neuron 95, 1306-1318.e5. doi: 10.1016/j. neuron.2017.08.038

Chuhma, N., Choi, W. Y., Mingote, S., and Rayport, S. (2009). Dopamine neuron glutamate cotransmission: frequency-dependent modulation in the mesoventromedial projection. Neuroscience 164, 1068-1083. doi: 10.1016/j. neuroscience.2009.08.057

Chung, E. K., Chen, L. W., Chan, Y. S., and Yung, K. K. (2008). Downregulation of glial glutamate transporters after dopamine denervation in the striatum of 6 hydroxydopamine-lesioned rats. J. Comp. Neurol. 511, 421-437. doi: 10.1002/ cne. 21852 da Silva, J. A., Tecuapetla, F., Paixao, V., and Costa, R. M. (2018). Dopamine neuron activity before action initiation gates and invigorates future movements. Nature 554, 244-248. doi: 10.1038/nature25457

Danbolt, N. C., Storm-Mathisen, J., and Kanner, B. I. (1992). An [Na+ + $\mathrm{K}+$ ]coupled L-glutamate transporter purified from rat brain is located in glial cell processes. Neuroscience 51, 295-310. doi: 10.1016/0306-4522(92)90316-t

Daniels, R. W., Collins, C. A., Chen, K., Gelfand, M. V., Featherstone, D. E., and DiAntonio, A. (2006). A single vesicular glutamate transporter is sufficient to fill a synaptic vesicle. Neuron 49, 11-16. doi: 10.1016/j.neuron.2005.11.032

Daniels, R. W., Miller, B. R., and DiAntonio, A. (2011). Increased vesicular glutamate transporter expression causes excitotoxic neurodegeneration. Neurobiol. Dis. 41, 415-420. doi: 10.1016/j.nbd.2010.10.009

Divito, C. B., Steece-Collier, K., Case, D. T., Williams, S. P., Stancati, J. A., Zhi, L., et al. (2015). Loss of VGLUT3 produces circadian-dependent hyperdopaminergia and ameliorates motor dysfunction and 1-dopa-mediated dyskinesias in a model of Parkinson's disease. J. Neurosci. 35, 14983-14999. doi: 10.1523/JNEUROSCI.2124-15.2015

Duerson, K., Woltjer, R. L., Mookherjee, P., Leverenz, J. B., Montine, T. J., Bird, T. D., et al. (2009). Detergent-insoluble EAAC1/EAAT3 aberrantly accumulates in hippocampal neurons of Alzheimer's disease patients. Brain Pathol. 19, 267-278. doi: 10.1111/j.1750-3639.2008.00186.x

El Arfani, A., Albertini, G., Bentea, E., Demuyser, T., Van Eeckhaut, A., Smolders, I., et al. (2015). Alterations in the motor cortical and striatal glutamatergic system and D-serine levels in the bilateral 6hydroxydopamine rat model for Parkinson's disease. Neurochem. Int. 88, 88-96. doi: 10.1016/j.neuint.2015.07.005

El Mestikawy, S., Wallen-Mackenzie, A., Fortin, G. M., Descarries, L., and Trudeau, L. E. (2011). From glutamate co-release to vesicular synergy: vesicular glutamate transporters. Nat. Rev. Neurosci. 12, 204-216. doi: 10.1038/nrn2969

Eliasof, S., Arriza, J. L., Leighton, B. H., Kavanaugh, M. P., and Amara, S. G. (1998). Excitatory amino acid transporters of the salamander retina: identification, localization, and function. J. Neurosci. 18, 698-712.

Fang, Y. Y., Zeng, P., Qu, N., Ning, L. N., Chu, J., Zhang, T., et al. (2018). Evidence of altered depression and dementia-related proteins in the brains of young rats after ovariectomy. J. Neurochem. 146, 703-721. doi: 10.1111/jnc.14537

Fattorini, G., Ciriachi, C., and Conti, F. (2017). Few, activity-dependent, and ubiquitous VGLUT1/VGAT terminals in rat and mouse brain. Front. Cell Neurosci. 11:229. doi: 10.3389/fncel.2017.00229

Firbank, M. J., Parikh, J., Murphy, N., Killen, A., Allan, C. L., Collerton, D., et al. (2018). Reduced occipital GABA in Parkinson disease with visual hallucinations. Neurology 91, e675-e685. doi: 10.1212/WNL.00000000000 06007

Frampton, J. E. (2014). Pramipexole extended-release: a review of its use in patients with Parkinson's disease. Drugs 74, 2175-2190. doi: 10.1007/s40265-014-03 22-325

Fremeau, R. T. Jr., Kam, K., Qureshi, T., Johnson, J., Copenhagen, D. R., et al. (2004). Vesicular glutamate transporters 1 and 2 target to functionally distinct synaptic release sites. Science 304, 1815-1819. doi: 10.1126/science.1097468

Gangarossa, G., Guzman, M., Prado, V. F., Prado, M. A., Daumas, S., El Mestikawy, S., et al. (2016). Role of the atypical vesicular glutamate transporter VGLUT3 in 1-DOPA-induced dyskinesia. Neurobiol. Dis. 87, 69-79. doi: 10.1016/j.nbd.2015. 12.010

Ghosh, M., Yang, Y., Rothstein, J. D., and Robinson, M. B. (2011). Nuclear factorkappaB contributes to neuron-dependent induction of glutamate transporter-1 expression in astrocytes. J. Neurosci. 31, 9159-9169. doi: 10.1523/JNEUROSCI. 0302-11.2011

Gibson, C. L., Balbona, J. T., Ashlin, N., Peter, R., Nguyen, K. C. Q., Hall, D. H., et al. (2018). Glial loss of the metallo $\beta$-lactamase domain containing protein, SWIP-10, induces age- and glutamate-signaling dependent, dopamine neuron degeneration. PLoS Genet. 14:e1007269. doi: 10.1371/journal.pgen.1007269

Golembiowska, K., Berghauzen-Maciejewska, K., Gorska, A., Kaminska, K., and Ossowska, K. (2013). A partial lesion of the substantia nigra pars compacta and retrorubral field decreases the harmaline-induced glutamate release in the rat cerebellum. Brain Res. 1537, 303-311. doi: 10.1016/j.brainres.2013.08.059

Granseth, B., Andersson, F. K., and Lindstrom, S. H. (2015). The initial stage of reversal learning is impaired in mice hemizygous for the vesicular glutamate transporter (VGluT1). Genes Brain Behav. 14, 477-485. doi: 10.1111/gbb.12230

Gras, C., Amilhon, B., Lepicard, E. M., Poirel, O., Vinatier, J., Herbin, M., et al. (2008). The vesicular glutamate transporter VGLUT3 synergizes striatal acetylcholine tone. Nat. Neurosci. 11, 292-300. doi: 10.1038/nn2052 
Greenamyre, J. T., Eller, R. V., Zhang, Z., Ovadia, A., Kurlan, R., and Gash, D. M. (1994). Antiparkinsonian effects of remacemide hydrochloride, a glutamate antagonist, in rodent and primate models of Parkinson's disease. Ann. Neurol. 35, 655-661. doi: 10.1002/ana.410350605

Haugeto, O., Ullensvang, K., Levy, L. M., Chaudhry, F. A., Honore, T., Nielsen, M., et al. (1996). Brain glutamate transporter proteins form homomultimers. J. Biol. Chem. 271, 27715-27722. doi: 10.1074/jbc.271.44.27715

Hayashi, M. K. (2018). Structure-Function relationship of transporters in the glutamate-glutamine cycle of the central nervous system. Int. J. Mol. Sci. 19:1177. doi: 10.3390/ijms19041177

Hayes, D., Wiessner, M., Rauen, T., and McBean, G. J. (2005). Transport of L-[14C]cystine and L-[14C]cysteine by subtypes of high affinity glutamate transporters over-expressed in HEK cells. Neurochem. Int. 46, 585-594. doi: 10.1016/j.neuint.2005.03.001

He, Y., and Casaccia-Bonnefil, P. (2008). The Yin and Yang of YY1 in the nervous system. J. Neurochem. 106, 1493-1502. doi: 10.1111/j.1471-4159.2008.05486.x

Herzog, E., Bellenchi, G. C., Gras, C., Bernard, V., Ravassard, P., Bedet, C., et al. (2001). The existence of a second vesicular glutamate transporter specifies subpopulations of glutamatergic neurons. J. Neurosci. 21:RC181.

Higley, M. J., Gittis, A. H., Oldenburg, I. A., Balthasar, N., Seal, R. P., Edwards, R. H., et al. (2011). Cholinergic interneurons mediate fast VGluT3-dependent glutamatergic transmission in the striatum. PLoS One 6:e19155. doi: 10.1371/ journal.pone.0019155

Holmer, H. K., Keyghobadi, M., Moore, C., and Meshul, C. K. (2005). 1-dopainduced reversal in striatal glutamate following partial depletion of nigrostriatal dopamine with 1-methyl-4-phenyl-1,2,3,6-tetrahydropyridine. Neuroscience 136, 333-341. doi: 10.1016/j.neuroscience.2005.08.003

Holmseth, S., Dehnes, Y., Huang, Y. H., Follin-Arbelet, V. V., Grutle, N. J., Mylonakou, M. N., et al. (2012). The density of EAAC1 (EAAT3) glutamate transporters expressed by neurons in the mammalian CNS. J. Neurosci. 32, 6000-6013. doi: 10.1523/JNEUROSCI.5347-11.2012

Hubsher, G., Haider, M., and Okun, M. S. (2012). Amantadine: the journey from fighting flu to treating Parkinson disease. Neurology 78, 1096-1099. doi: 10. 1212/WNL.0b013e31824e8f0d

Ibrahim, K. S., Abd-Elrahman, K. S., El Mestikawy, S., and Ferguson, S. S. G. (2020). Targeting vesicular glutamate transporter machinery: implications on metabotropic glutamate receptor 5 signaling and behavior. Mol. Pharmacol. 98, 314-327. doi: 10.1124/molpharm.120.000089

Iderberg, H., McCreary, A. C., Varney, M. A., Cenci, M. A., and NewmanTancredi, A. (2015). Activity of serotonin 5-HT(1A) receptor 'biased agonists' in rat models of Parkinson's disease and L-DOPA-induced dyskinesia. Neuropharmacology 93, 52-67. doi: 10.1016/j.neuropharm.2015.01.012

Jen, J. C., Wan, J., Palos, T. P., Howard, B. D., and Baloh, R. W. (2005). Mutation in the glutamate transporter EAAT1 causes episodic ataxia, hemiplegia, and seizures. Neurology 65, 529-534. doi: 10.1212/01.wnl.0000172638.58172.5a

Jia, M., Njapo, S. A., Rastogi, V., and Hedna, V. S. (2015). Taming glutamate excitotoxicity: strategic pathway modulation for neuroprotection. CNS Drugs 29, 153-162. doi: 10.1007/s40263-015-0225-223

Jiang, N. W., Wang, D. J., Xie, Y. J., Zhou, L., Su, L. D., Li, H., et al. (2016). Downregulation of glutamate transporter EAAT4 by conditional knockout of Rheb1 in cerebellar purkinje cells. Cerebellum 15, 314-321. doi: 10.1007/ s12311-015-0701-709

Johnson, J. Jr., Pajarillo, E. A. B., Taka, E., Reams, R., Son, D. S., et al. (2018). Valproate and sodium butyrate attenuate manganese-decreased locomotor activity and astrocytic glutamate transporters expression in mice. Neurotoxicology 64, 230-239. doi: 10.1016/j.neuro.2017.06.007

Jourdain, V. A., Morin, N., Gregoire, L., Morissette, M., and Di Paolo, T. (2015). Changes in glutamate receptors in dyskinetic parkinsonian monkeys after unilateral subthalamotomy. J. Neurosurg. 123, 1383-1393. doi: 10.3171/2014. 10.JNS141570

Kalia, L. V., and Lang, A. E. (2015). Parkinson's disease. Lancet 386, 896-912. doi: 10.1016/S0140-6736(14)61393-61393

Karki, P., Smith, K., Johnson, J. Jr., Aschner, M., and Lee, E. Y. (2015a). Genetic dys-regulation of astrocytic glutamate transporter EAAT2 and its implications in neurological disorders and manganese toxicity. Neurochem. Res. 40, 380-388. doi: 10.1007/s11064-014-1391-1392

Karki, P., Smith, K., Johnson, J. Jr., Aschner, M., and Lee, E. (2015b). Role of transcription factor yin yang 1 in manganese-induced reduction of astrocytic glutamate transporters: putative mechanism for manganeseinduced neurotoxicity. Neurochem. Int. 88, 53-59. doi: 10.1016/j.neuint.2014. 08.002

Kashani, A., Betancur, C., Giros, B., Hirsch, E., and El Mestikawy, S. (2007). Altered expression of vesicular glutamate transporters VGLUT1 and VGLUT2 in Parkinson disease. Neurobiol. Aging 28, 568-578. doi: 10.1016/j.neurobiolaging. 2006.02.010

Keating, G. M., and Lyseng-Williamson, K. A. (2005). Tolcapone: a review of its use in the management of Parkinson's disease. CNS Drugs 19, 165-184. doi: 10.2165/00023210-200519020-200519026

Khadrawy, Y. A., Mourad, I. M., Mohammed, H. S., Noor, N. A., and Aboul Ezz, H. S. (2017). Cerebellar neurochemical and histopathological changes in rat model of Parkinson's disease induced by intrastriatal injection of rotenone. Gen Physiol. Biophys. 36, 99-108. doi: 10.4149/gpb_2016031

Kintz, N., Petzinger, G. M., Akopian, G., Ptasnik, S., Williams, C., Jakowec, M. W., et al. (2013). Exercise modifies alpha-amino-3-hydroxy-5-methyl-4isoxazolepropionic acid receptor expression in striatopallidal neurons in the 1-methyl-4-phenyl-1,2,3,6-tetrahydropyridine-lesioned mouse. J. Neurosci. Res. 91, 1492-1507. doi: 10.1002/jnr.23260

Kouwenhoven, W. M., Fortin, G., Penttinen, A. M., Florence, C., Delignat-Lavaud, B., Bourque, M. J., et al. (2020). VGluT2 expression in dopamine neurons contributes to postlesional striatal reinnervation. J. Neurosci. 40, 8262-8275. doi: 10.1523/JNEUROSCI.0823-20.2020

Kovermann, P., Untiet, V., Kolobkova, Y., Engels, M., Baader, S., Schilling, K., et al. (2020). Increased glutamate transporter-associated anion currents cause glial apoptosis in episodic ataxia 6. Brain Commun. 2:fcaa022. doi: 10.1093/ braincomms/fcaa022

Kumakura, Y., Danielsen, E. H., Gjedde, A., Vernaleken, I., Buchholz, H. G., Heinz, A., et al. (2010). Elevated [(18)F]FDOPA utilization in the periaqueductal gray and medial nucleus accumbens of patients with early Parkinson's disease. Neuroimage 49, 2933-2939. doi: 10.1016/j.neuroimage.2009.11.035

Lee, D. G., Kam, M. K., Lee, S. R., Lee, H. J., and Lee, D. S. (2020). Peroxiredoxin 5 deficiency exacerbates iron overload-induced neuronal death via ER-mediated mitochondrial fission in mouse hippocampus. Cell Death Dis. 11:204. doi: 10. 1038/s41419-020-2402-2407

Lee, S. K., Sillitoe, R. V., Silva, C., Martina, M., and Sekerkova, G. (2015). alphaSynuclein expression in the mouse cerebellum is restricted to VGluT1 excitatory terminals and is enriched in unipolar brush cells. Cerebellum 14, 516-527. doi: 10.1007/s12311-015-0673-679

Leung, T. C., Lui, C. N., Chen, L. W., Yung, W. H., Chan, Y. S., and Yung, K. K. (2012). Ceftriaxone ameliorates motor deficits and protects dopaminergic neurons in 6-hydroxydopamine-lesioned rats. ACS Chem. Neurosci. 3, 22-30. doi: $10.1021 / \mathrm{cn} 200072 \mathrm{~h}$

Levite, M., Zelig, D., Friedman, A., Ilouz, N., Eilam, R., Bromberg, Z., et al. (2020). Dual-Targeted autoimmune sword in fatal epilepsy: patient's glutamate receptor AMPA GluR3B peptide autoimmune antibodies bind, induce Reactive Oxygen Species (ROS) in, and kill both human neural cells and T cells. J. Autoimmun 112:102462. doi: 10.1016/j.jaut.2020.102462

Li, W., Gao, H., and Li, W. (2020a). Effects of combined bushen zhichan recipe and levodopa in a rodent model of Parkinson disease: potential mechanisms. Med. Sci. Monit. 26:e922345. doi: 10.12659/MSM.922345

Li, X., Zhang, J., Rong, H., Zhang, X., and Dong, M. (2020b). Ferulic acid ameliorates $\mathrm{MPP}(+) / \mathrm{MPTP}-$ Induced oxidative stress via ERK1/2-Dependent Nrf2 activation: translational implications for Parkinson disease treatment. Mol. Neurobiol. 57, 2981-2995. doi: 10.1007/s12035-020-01934-1931

Lim, J., Lam, Y. C., Kistler, J., and Donaldson, P. J. (2005). Molecular characterization of the cystine/glutamate exchanger and the excitatory amino acid transporters in the rat lens. Invest. Ophthalmol. Vis. Sci. 46, 2869-2877. doi: 10.1167/iovs.05-0156

Lin, C. L., Kong, Q., Cuny, G. D., and Glicksman, M. A. (2012). Glutamate transporter EAAT2: a new target for the treatment of neurodegenerative diseases. Future Med. Chem. 4, 1689-1700. doi: 10.4155/fmc.12.122

Liu, J., and Wang, L. N. (2018). The efficacy and safety of riluzole for neurodegenerative movement disorders: a systematic review with metaanalysis. Drug Deliv. 25, 43-48. doi: 10.1080/10717544.2017.1413446

Liu, Y., Zong, X., Huang, J., Guan, Y., Li, Y., Du, T., et al. (2019). Ginsenoside Rb1 regulates prefrontal cortical GABAergic transmission in MPTP-treated mice. Aging (Albany NY) 11, 5008-5034. doi: 10.18632/aging.102095 
Mann, E., Jackson, M., Lincoln, L., Fisher, R., Rose, S., and Duty, S. (2020). Antiparkinsonian effects of a metabotropic glutamate receptor 4 Agonist in MPTP-treated marmosets. J. Parkinsons Dis. 10, 959-967. doi: 10.3233/JPD191824

Massie, A., Cnops, L., Smolders, I., McCullumsmith, R., Kooijman, R., Kwak, S., et al. (2008). High-affinity $\mathrm{Na}+/ \mathrm{K}+$-dependent glutamate transporter EAAT4 is expressed throughout the rat fore- and midbrain. J. Comp. Neurol. 511, 155-172. doi: 10.1002/cne.21823

Massie, A., Schallier, A., Vermoesen, K., Arckens, L., and Michotte, Y. (2010). Biphasic and bilateral changes in striatal VGLUT1 and 2 protein expression in hemi-Parkinson rats. Neurochem. Int. 57, 111-118. doi: 10.1016/j.neuint.2010. 04.019

Matheson, A. J., and Spencer, C. M. (2000). Ropinirole: a review of its use in the management of Parkinson's disease. Drugs 60, 115-137. doi: 10.2165/00003495200060010-200060017

Mathews, G. C., and Diamond, J. S. (2003). Neuronal glutamate uptake Contributes to GABA synthesis and inhibitory synaptic strength. J. Neurosci. 23, 2040-2048.

Matsuura, S., Ikegaya, Y., Yamada, M. K., Nishiyama, N., and Matsuki, N. (2002). Endothelin downregulates the glutamate transporter GLAST in cAMPdifferentiated astrocytes in vitro. Glia 37, 178-182. doi: 10.1002/glia.10020

Menard, C., and Quirion, R. (2012). Group 1 metabotropic glutamate receptor function and its regulation of learning and memory in the aging brain. Front. Pharmacol. 3:182. doi: 10.3389/fphar.2012.00182

Mishra, P. S., Dhull, D. K., Nalini, A., Vijayalakshmi, K., Sathyaprabha, T. N., Alladi, P. A., et al. (2016). Astroglia acquires a toxic neuroinflammatory role in response to the cerebrospinal fluid from amyotrophic lateral sclerosis patients. J. Neuroinflammation 13:212. doi: 10.1186/s12974-016-0698-690

Moore, C., Xu, M., Bohlen, J. K., and Meshul, C. K. (2020). Differential ultrastructural alterations in the Vglut2 glutamatergic input to the substantia nigra pars compacta/pars reticulata following nigrostriatal dopamine loss in a progressive mouse model of Parkinson's disease. Eur. J. Neurosci. 53, 20612077. doi: 10.1111/ejn.14894

Morales, M., and Margolis, E. B. (2017). Ventral tegmental area: cellular heterogeneity, connectivity and behaviour. Nat. Rev. Neurosci. 18, 73-85. doi: 10.1038/nrn.2016.165

Morales, M., and Root, D. H. (2014). Glutamate neurons within the midbrain dopamine regions. Neuroscience 282, 60-68. doi: 10.1016/j.neuroscience.2014. 05.032

Mori, T., Tateishi, N., Kagamiishi, Y., Shimoda, T., Satoh, S., Ono, S., et al. (2004). Attenuation of a delayed increase in the extracellular glutamate level in the peri-infarct area following focal cerebral ischemia by a novel agent ONO-2506. Neurochem. Int. 45, 381-387. doi: 10.1016/j.neuint.2003.06.001

Muller, T. (2015). The safety of istradefylline for the treatment of Parkinson's disease. Expert Opin. Drug. Saf. 14, 769-775. doi: 10.1517/14740338.2015. 1014798

Nafia, I., Re, D. B., Masmejean, F., Melon, C., Kachidian, P., Kerkerian-Le Goff, L., et al. (2008). Preferential vulnerability of mesencephalic dopamine neurons to glutamate transporter dysfunction. J. Neurochem. 105, 484-496. doi: 10.1111/j. 1471-4159.2007.05146.x

Neal, M., Luo, J., Harischandra, D. S., Gordon, R., Sarkar, S., Jin, H., et al. (2018). Prokineticin-2 promotes chemotaxis and alternative A2 reactivity of astrocytes. Glia 66, 2137-2157. doi: 10.1002/glia.23467

Nelson, A. B., Bussert, T. G., Kreitzer, A. C., and Seal, R. P. (2014). Striatal cholinergic neurotransmission requires VGLUT3. J. Neurosci. 34, 8772-8777. doi: 10.1523/JNEUROSCI.0901-14.2014

Ni, B., Wu, X., Yan, G. M., Wang, J., and Paul, S. M. (1995). Regional expression and cellular localization of the $\mathrm{Na}(+)$-dependent inorganic phosphate cotransporter of rat brain. J. Neurosci. 15, 5789-5799.

Nuzzo, T., Punzo, D., Devoto, P., Rosini, E., Paciotti, S., Sacchi, S., et al. (2019). The levels of the NMDA receptor co-agonist D-serine are reduced in the substantia nigra of MPTP-lesioned macaques and in the cerebrospinal fluid of Parkinson's disease patients. Sci. Rep. 9:8898. doi: 10.1038/s41598-019-4541945411

Oertel, W., and Schulz, J. B. (2016). Current and experimental treatments of Parkinson disease: a guide for neuroscientists. J. Neurochem. 139(Suppl. 1), 325-337. doi: 10.1111/jnc.13750

Olivares, D., Deshpande, V. K., Shi, Y., Lahiri, D. K., Greig, N. H., Rogers, J. T., et al. (2012). N-methyl D-aspartate (n.d.) receptor antagonists and memantine treatment for Alzheimer's disease, vascular dementia and Parkinson's disease. Curr. Alzheimer Res. 9, 746-758. doi: 10.2174/156720512801322564

Palakurthi, B., and Burugupally, S. P. (2019). Postural instability in parkinson's disease: a review. Brain Sci. 9:239. doi: 10.3390/brainsci9090239

Palos, T. P., Zheng, S., and Howard, B. D. (1999). Wnt signaling induces GLT-1 expression in rat C6 glioma cells. J. Neurochem. 73, 1012-1023. doi: 10.1046/j. 1471-4159.1999.0731012.x

Parinejad, N., Peco, E., Ferreira, T., Stacey, S. M., and van Meyel, D. J. (2016). Disruption of an EAAT-Mediated chloride channel in a Drosophila model of ataxia. J. Neurosci. 36, 7640-7647. doi: 10.1523/JNEUROSCI.019716.2016

Park, H., Kang, S., Nam, E., Suh, Y. H., and Chang, K. A. (2019). The protective effects of PSM-04 against beta amyloid-induced neurotoxicity in primary cortical neurons and an animal model of Alzheimer's disease. Front. Pharmacol. 10:2. doi: 10.3389/fphar.2019.00002

Park, J. H., Burgess, J. D., Faroqi, A. H., DeMeo, N. N., Fiesel, F. C., Springer, W., et al. (2020). Alpha-synuclein-induced mitochondrial dysfunction is mediated via a sirtuin 3-dependent pathway. Mol. Neurodegener. 15:5. doi: 10.1186/ s13024-019-0349-x

Parkin, G. M., Udawela, M., Gibbons, A., and Dean, B. (2018). Glutamate transporters, EAAT1 and EAAT2, are potentially important in the pathophysiology and treatment of schizophrenia and affective disorders. World J. Psychiatry 8, 51-63. doi: 10.5498/wjp.v8.i2.51

Perez-Lloret, S., and Rascol, O. (2016). Piribedil for the treatment of motor and non-motor symptoms of Parkinson disease. CNS Drugs 30, 703-717. doi: 10. 1007/s40263-016-0360-365

Perkins, E. M., Clarkson, Y. L., Sabatier, N., Longhurst, D. M., Millward, C. P., Jack, J., et al. (2010). Loss of beta-III spectrin leads to Purkinje cell dysfunction recapitulating the behavior and neuropathology of spinocerebellar ataxia type 5 in humans. J. Neurosci. 30, 4857-4867. doi: 10.1523/JNEUROSCI.606509.2010

Pflibsen, L., Stang, K. A., Sconce, M. D., Wilson, V. B., Hood, R. L., Meshul, C. K., et al. (2015). Executive function deficits and glutamatergic protein alterations in a progressive 1-methyl-4-phenyl-1,2,3,6-tetrahydropyridine mouse model of Parkinson's disease. J. Neurosci. Res. 93, 1849-1864. doi: 10.1002/jnr.23638

Picaud, S., Larsson, H. P., Wellis, D. P., Lecar, H., and Werblin, F. (1995). Cone photoreceptors respond to their own glutamate release in the tiger salamander. Proc. Natl. Acad. Sci. U S A. 92, 9417-9421. doi: 10.1073/pnas.92.20.9417

Pow, D. V., and Barnett, N. L. (2000). Developmental expression of excitatory amino acid transporter 5: a photoreceptor and bipolar cell glutamate transporter in rat retina. Neurosci. Lett. 280, 21-24. doi: 10.1016/s03043940(99)00988-x

Raju, D. V., Ahern, T. H., Shah, D. J., Wright, T. M., Standaert, D. G., Hall, R. A., et al. (2008). Differential synaptic plasticity of the corticostriatal and thalamostriatal systems in an MPTP-treated monkey model of parkinsonism. Eur. J. Neurosci. 27, 1647-1658. doi: 10.1111/j.1460-9568.2008.06136.x

Rakhade, S. N., and Loeb, J. A. (2008). Focal reduction of neuronal glutamate transporters in human neocortical epilepsy. Epilepsia 49, 226-236. doi: 10.1111/ j.1528-1167.2007.01310.x

Rani, L., and Mondal, A. C. (2020). Emerging concepts of mitochondrial dysfunction in Parkinson's disease progression: pathogenic and therapeutic implications. Mitochondrion 50, 25-34. doi: 10.1016/j.mito.2019.09.010

Robert, S. M., Ogunrinu-Babarinde, T., Holt, K. T., and Sontheimer, H. (2014). Role of glutamate transporters in redox homeostasis of the brain. Neurochem. Int. 73, 181-191. doi: 10.1016/j.neuint.2014.01.001

Rothstein, J. D., Dykes-Hoberg, M., Pardo, C. A., Bristol, L. A., Jin, L., Kuncl, R. W., et al. (1996). Knockout of glutamate transporters reveals a major role for astroglial transport in excitotoxicity and clearance of glutamate. Neuron 16, 675-686. doi: 10.1016/s0896-6273(00)80086-80080

Rothstein, J. D., Martin, L., Levey, A. I., Dykes-Hoberg, M., Jin, L., Wu, D., et al. (1994). Localization of neuronal and glial glutamate transporters. Neuron 13, 713-725. doi: 10.1016/0896-6273(94)90038-90038

Sahli, Z. T., and Tarazi, F. I. (2018). Pimavanserin: novel pharmacotherapy for Parkinson's disease psychosis. Expert Opin. Drug Discov. 13, 103-110. doi: 10.1080/17460441.2018.1394838

Sattler, R., and Rothstein, J. D. (2006). Regulation and dysregulation of glutamate transporters. Handb. Exp. Pharmacol. 175, 277-303. doi: 10.1007/3-540-297 84-7_14 
Schapira, A. H. (2010). Safinamide in the treatment of Parkinson's disease. Expert Opin. Pharmacother. 11, 2261-2268. doi: 10.1517/14656566.2010.511612

Schenck, S., Wojcik, S. M., Brose, N., and Takamori, S. (2009). A chloride conductance in VGLUT1 underlies maximal glutamate loading into synaptic vesicles. Nat. Neurosci. 12, 156-162. doi: 10.1038/nn.2248

Schrag, A. (2005). Entacapone in the treatment of Parkinson's disease. Lancet Neurol. 4, 366-370. doi: 10.1016/S1474-4422(05)70098-70093

Schweizer, N., Pupe, S., Arvidsson, E., Nordenankar, K., Smith-Anttila, C. J., Mahmoudi, S., et al. (2014). Limiting glutamate transmission in a Vglut2expressing subpopulation of the subthalamic nucleus is sufficient to cause hyperlocomotion. Proc. Natl. Acad. Sci. U S A. 111, 7837-7842. doi: 10.1073/ pnas. 1323499111

Schweizer, N., Viereckel, T., Smith-Anttila, C. J., Nordenankar, K., Arvidsson, E., Mahmoudi, S., et al. (2016). Reduced Vglut2/Slc17a6 gene expression levels throughout the mouse subthalamic nucleus cause cell loss and structural disorganization followed by increased motor activity and decreased sugar consumption. eNeuro 3:ENEURO.0264-16.2016. doi: 10.1523/ENEURO.026416.2016

Sepkuty, J. P., Cohen, A. S., Eccles, C., Rafiq, A., Behar, K., Ganel, R., et al. (2002). A neuronal glutamate transporter contributes to neurotransmitter GABA synthesis and epilepsy. J. Neurosci. 22, 6372-6379.

Serra, H. G., Byam, C. E., Lande, J. D., Tousey, S. K., Zoghbi, H. Y., and Orr, H. T. (2004). Gene profiling links SCA1 pathophysiology to glutamate signaling in Purkinje cells of transgenic mice. Hum. Mol. Genet. 13, 2535-2543. doi: $10.1093 / \mathrm{hmg} / \mathrm{ddh} 268$

Shang, Y. C., Chong, Z. Z., Hou, J., and Maiese, K. (2010). Wnt1, FoxO3a, and NFkappaB oversee microglial integrity and activation during oxidant stress. Cell Signal. 22, 1317-1329. doi: 10.1016/j.cellsig.2010.04.009

Shashidharan, P., Huntley, G. W., Murray, J. M., Buku, A., Moran, T., Walsh, M. J., et al. (1997). Immunohistochemical localization of the neuron-specific glutamate transporter EAAC1 (EAAT3) in rat brain and spinal cord revealed by a novel monoclonal antibody. Brain Res. 773, 139-148. doi: 10.1016/s00068993(97)00921-929

Shen, H., Marino, R. A. M., McDevitt, R. A., Bi, G. H., Chen, K., Madeo, G., et al. (2018). Genetic deletion of vesicular glutamate transporter in dopamine neurons increases vulnerability to MPTP-induced neurotoxicity in mice. Proc. Natl. Acad. Sci. U S A. 115, E11532-E11541. doi: 10.1073/pnas.1800886115

Singh, S., Mishra, A., Srivastava, N., Shukla, R., and Shukla, S. (2018). Acetyl-L-Carnitine via upegulating dopamine D1 receptor and attenuating microglial activation prevents neuronal loss and improves memory functions in parkinsonian rats. Mol. Neurobiol. 55, 583-602. doi: 10.1007/s12035-016-02 93-295

Son, Y., Byun, S. J., and Pae, H. O. (2013). Involvement of heme oxygenase-1 expression in neuroprotection by piceatannol, a natural analog and a metabolite of resveratrol, against glutamate-mediated oxidative injury in HT22 neuronal cells. Amino Acids 45, 393-401. doi: 10.1007/s00726-013-1518-1519

Stacey, S. M., Muraro, N. I., Peco, E., Labbe, A., Thomas, G. B., Baines, R. A., et al. (2010). Drosophila glial glutamate transporter Eaat1 is regulated by fringemediated notch signaling and is essential for larval locomotion. J. Neurosci. 30, 14446-14457. doi: 10.1523/JNEUROSCI.1021-10.2010

Steinkellner, T., Zell, V., Farino, Z. J., Sonders, M. S., Villeneuve, M., Freyberg, R. J., et al. (2018). Role for VGLUT2 in selective vulnerability of midbrain dopamine neurons. J. Clin. Invest. 128, 774-788. doi: 10.1172/JCI95795

Szoko, E., Tabi, T., Riederer, P., Vecsei, L., and Magyar, K. (2018). Pharmacological aspects of the neuroprotective effects of irreversible MAO-B inhibitors, selegiline and rasagiline, in Parkinson's disease. J. Neural. Transm. (Vienna) 125, 1735-1749. doi: 10.1007/s00702-018-1853-1859

Takada, M., Sugimoto, T., and Hattori, T. (1993). MPTP neurotoxicity to cerebellar Purkinje cells in mice. Neurosci. Lett. 150, 49-52. doi: 10.1016/0304-3940(93) 90105- $\mathrm{t}$

Takahashi, S., Tohgi, H., Yonezawa, H., Obara, S., and Yamazaki, E. (1999). The effect of trihexyphenidyl, an anticholinergic agent, on regional cerebral blood flow and oxygen metabolism in patients with Parkinson's disease. J. Neurol. Sci. 167, 56-61. doi: 10.1016/s0022-510x(99)00142-142

Tamano, H., Nishio, R., Morioka, H., Furuhata, R., Komata, Y., and Takeda, A. (2019). Paraquat as an environmental risk factor in Parkinson's disease accelerates age-related degeneration via rapid influx of extracellular $\mathrm{Zn}(2+)$ into nigral dopaminergic neurons. Mol. Neurobiol. 56, 7789-7799. doi: 10.1007/ s12035-019-01642-1645

Tanaka, K., Watase, K., Manabe, T., Yamada, K., Watanabe, M., Takahashi, K., et al. (1997). Epilepsy and exacerbation of brain injury in mice lacking the glutamate transporter GLT-1. Science 276, 1699-1702. doi: 10.1126/science.276.5319.1699

Tikka, T., Usenius, T., Tenhunen, M., Keinanen, R., and Koistinaho, J. (2001). Tetracycline derivatives and ceftriaxone, a cephalosporin antibiotic, protect neurons against apoptosis induced by ionizing radiation. J. Neurochem. 78, 1409-1414. doi: 10.1046/j.1471-4159.2001.00543.x

Trudeau, L. E., Hnasko, T. S., Wallen-Mackenzie, A., Morales, M., Rayport, S., and Sulzer, D. (2014). The multilingual nature of dopamine neurons. Prog. Brain Res. 211, 141-164. doi: 10.1016/B978-0-444-63425-2.00006-4

Untiet, V., Kovermann, P., Gerkau, N. J., Gensch, T., Rose, C. R., and Fahlke, C. (2017). Glutamate transporter-associated anion channels adjust intracellular chloride concentrations during glial maturation. Glia 65, 388-400. doi: 10.1002/ glia.23098

Wang, J., Wang, F., Mai, D., and Qu, S. (2020). Molecular mechanisms of glutamate toxicity in Parkinson's disease. Front. Neurosci. 14:585584. doi: 10.3389/fnins. 2020.585584

Wang, W., Zeng, F., Hu, Y., and Li, X. (2019). A mini-review of the role of glutamate transporter in drug addiction. Front. Neurol. 10:1123. doi: 10.3389/ fneur.2019.01123

Wang, Y., Wang, Y., Liu, J., and Wang, X. (2018). Electroacupuncture alleviates motor symptoms and up-regulates vesicular glutamatergic transporter 1 expression in the subthalamic nucleus in a unilateral 6-hydroxydopaminelesioned hemi-parkinsonian rat model. Neurosci. Bull. 34, 476-484. doi: 10. 1007/s12264-018-0213-y

Wang, Z., Wei, X., Liu, K., Zhang, X., Yang, F., Zhang, H., et al. (2013). NOX2 deficiency ameliorates cerebral injury through reduction of complexin IImediated glutamate excitotoxicity in experimental stroke. Free Radic Biol. Med. 65, 942-951. doi: 10.1016/j.freeradbiomed.2013.08.166

Wei, L., Chen, C., Ding, L., Mo, M., Zou, J., Lu, Z., et al. (2019). Wnt1 promotes EAAT2 expression and mediates the protective effects of astrocytes on dopaminergic cells in Parkinson's disease. Neural. Plast. 2019:1247276. doi: $10.1155 / 2019 / 1247276$

Wersinger, E., Schwab, Y., Sahel, J. A., Rendon, A., Pow, D. V., Picaud, S., et al. (2006). The glutamate transporter EAAT5 works as a presynaptic receptor in mouse rod bipolar cells. J. Physiol. 577(Pt 1), 221-234. doi: 10.1113/jphysiol. 2006.118281

Wilson, N. R., Kang, J., Hueske, E. V., Leung, T., Varoqui, H., Murnick, J. G., et al. (2005). Presynaptic regulation of quantal size by the vesicular glutamate transporter VGLUT1. J. Neurosci. 25, 6221-6234. doi: 10.1523/JNEUROSCI. 3003-04.2005

Wojcik, S. M., Rhee, J. S., Herzog, E., Sigler, A., Jahn, R., Takamori, S., et al. (2004). An essential role for vesicular glutamate transporter 1 (VGLUT1) in postnatal development and control of quantal size. Proc. Natl. Acad. Sci. U S A. 101, 7158-7163. doi: 10.1073/pnas.0401764101

Wu, D. M., Wang, S., Wen, X., Han, X. R., Wang, Y. J., Shen, M., et al. (2019). Suppression of microRNA-342-3p increases glutamate transporters and prevents dopaminergic neuron loss through activating the Wnt signaling pathway via p21-activated kinase 1 in mice with Parkinson's disease. J. Cell Physiol. 234, 9033-9044. doi: 10.1002/jcp.27577

Xu, S. F., Zhang, Y. H., Wang, S., Pang, Z. Q., Fan, Y. G., Li, J. Y., et al. (2019). Lactoferrin ameliorates dopaminergic neurodegeneration and motor deficits in MPTP-treated mice. Redox. Biol. 21:101090. doi: 10.1016/j.redox.2018.10 1090

Yang, X., Yang, H., Wu, F., Qi, Z., Li, J., Xu, B., et al. (2018). Mn inhibits GSH synthesis via downregulation of neuronal EAAC1 and astrocytic xCT to cause oxidative damage in the striatum of mice. Oxid. Med. Cell Longev. 2018:4235695. doi: 10.1155/2018/4235695

Zerangue, N., and Kavanaugh, M. P. (1996). Flux coupling in a neuronal glutamate transporter. Nature 383, 634-637. doi: 10.1038/383634a0

Zhang, F. X., Ge, S. N., Dong, Y. L., Shi, J., Feng, Y. P., Li, Y., et al. (2018a). Vesicular glutamate transporter isoforms: the essential players in the somatosensory systems. Prog. Neurobiol. 171, 72-89. doi: 10.1016/j.pneurobio.2018.09.006

Zhang, Y. L., Liu, Y., Kang, X. P., Dou, C. Y., Zhuo, R. G., Huang, S. Q., et al. (2018b). Ginsenoside Rb1 confers neuroprotection via promotion of glutamate 
transporters in a mouse model of Parkinson's disease. Neuropharmacology 131, 223-237. doi: 10.1016/j.neuropharm.2017.12.012

Zhang, Y., Meng, X., Jiao, Z., Liu, Y., Zhang, X., and Qu, S. (2020). Generation of a novel mouse model of Parkinson's disease via targeted knockdown of glutamate transporter GLT-1 in the substantia nigra. ACS Chem. Neurosci. 11, 406-417. doi: 10.1021/acschemneuro.9b00609

Zheng, Q., Huang, T., Zhang, L., Zhou, Y., Luo, H., Xu, H., et al. (2016). Dysregulation of ubiquitin-proteasome system in neurodegenerative diseases. Front. Aging Neurosci. 8:303. doi: 10.3389/fnagi.2016.00303

Zhou, L., Yang, L., Li, Y. J., Mei, R., Yu, H. L., Gong, Y., et al. (2018). MicroRNA-128 protects dopamine neurons from apoptosis and upregulates the expression of excitatory amino acid transporter 4 in Parkinson's disease by binding to AXIN1. Cell Physiol. Biochem. 51, 2275-2289. doi: 10.1159/000495872
Zhou, Y., and Danbolt, N. C. (2013). GABA and glutamate transporters in brain. Front. Endocrinol. (Lausanne) 4:165. doi: 10.3389/fendo.2013.00165

Conflict of Interest: The authors declare that the research was conducted in the absence of any commercial or financial relationships that could be construed as a potential conflict of interest.

Copyright (c) $2021 \mathrm{Li}$, Wang, Yan and Zeng. This is an open-access article distributed under the terms of the Creative Commons Attribution License (CC BY). The use, distribution or reproduction in other forums is permitted, provided the original author(s) and the copyright owner(s) are credited and that the original publication in this journal is cited, in accordance with accepted academic practice. No use, distribution or reproduction is permitted which does not comply with these terms. 